\title{
Mood, emotions, and behaviors of children during the COVID-19 pandemic in the Autonomous City of Buenos Aires
}

\author{
Laura Cohen Arazi ${ }^{a}(\mathbb{D})$, Mariela García ${ }^{(\mathbb{D})}$, Débora Berdecio Salvatierra ${ }^{a}(\mathbb{D})$, \\ Susana Villa Novab ${ }^{(\mathbb{D})}$, Florencia Curi Mello ${ }^{a}$ (D) Mónica Garrido ${ }^{a}$ (D), \\ Agustina Smitarello $^{a}(\mathbb{D})$, Adriana Alberti ${ }^{a}(\mathbb{D})$
}

\begin{abstract}
Introduction. Changes in daily routine and social fabric resulting from the COVID-19 pandemic had an effect on children and adolescents. The objective of this study was to know the mood, emotions, and behaviors of children and adolescents during the COVID-19 lockdown.

Population and methods. This was a prospective, descriptive, cross-sectional study. Parents and/ or caregivers of children and adolescents aged 3-15 years in the Autonomous City of Buenos Aires were asked about their perceptions of the mood, behaviors, and emotions of children and adolescents during the lockdown.

Results. A total of 1080 questionnaires were included. Results showed that $81 \%$ of parents and / or caregivers observed changes in children and adolescents emotional health; $76 \%$ referred that children aged 3-5 years were bored, angry, and upset. They also observed an increase in crying spells (52\%) and regression to behaviors that had been outgrown (29\%).

In the 6-11-year-old group, $43 \%$ showed difficulty focusing.

Adults noticed that 3 out of 10 adolescents aged 12-15 years discontinued activities they used to enjoy and were sad and worried.

Conclusion. The COVID-19 pandemic impacted on the mood, behaviors, and emotions of children and adolescents. Negative feelings prevailed, such as boredom, sadness, anxiety, and worry. Key words: pandemics, COVID-19, mental health, pediatrics.
\end{abstract}

a. Hospital General de Agudos Dr. Juan A. Fernández, Autonomous City of Buenos Aires, Argentina.

E-mail address:

Laura Cohen Arazi:

lauracohenarazi@

hotmail.com

Funding:

None.

Conflict of interest:

None.

Received: 5-19-2021

Accepted: 9-17-2021

\section{INTRODUCTION}

In the context of the worldwide COVID-19 pandemic, in March 2020, Argentina established a preventive and mandatory social isolation policy (ASPO, for its acronym in Spanish), ${ }^{1}$ which implied the suspension of inperson classes nationwide, ${ }^{2}$ a measure that lasted 7 months. During the COVID-19 pandemic, the United Nations Educational, Scientific and Cultural Organization (UNESCO) estimated that approximately 1.38 billion children missed in-person education due to the closing of schools and daycare centers. ${ }^{3}$ Adaptation to these changes affected especially children and adolescents, who may be deemed as the hidden victims of the pandemic. ${ }^{4}$ Although they were not part of risk groups in terms of physical health, they suffered the impact on their habits, routines, and social structures, basic factors that promote resilience to traumatic events. ${ }^{5}$ They experienced changes in education, nutrition, physical and mental health, leisure, and recreation, dimensions that have a direct impact on childhood. In addition, children and adolescents were exposed to large quantities of information and had to live with the repercussions. This had a greater effect on vulnerable and socially excluded populations.

\section{OBJECTIVES}

- To know the mood and behaviors of children and adolescents during the mandatory social isolation.

- To describe how children and adolescents received information about the COVID-19 pandemic. 


\section{POPULATION AND METHODS Population}

Children and adolescents aged 3-15 years from the Autonomous City of Buenos Aires (CABA). Based on the population projections by age group and district described in the National Census of 2010, as of July $1^{\text {st }}, 2020$, the population aged 0 -14 years was 604942 inhabitants. ${ }^{6,7}$

\section{Study design}

This was a prospective, descriptive, crosssectional study.

\section{Sample}

The sample included parents and/or caregivers of children and adolescents aged 3-15 years living in the CABA who attended the Department of Pediatrics of Hospital General de Agudos Dr. Juan A. Fernández.

\section{Data collection}

Data were collected using a questionnaire developed by the authors in Google Form ${ }^{\circledR}$ (Annex), which was self-administered and anonymous. It was disseminated via WhatsApp ${ }^{\circledR}$ during November and December 2020, after performing a pretest. It is worth noting that the survey was distributed among all patients who attended the hospital's Department of Pediatrics and lived in the CABA, whose medical record included a mobile phone number so that they could receive the survey via WhatsApp ${ }^{\circledR}$.

\section{Variables and statistical analysis}

Parents and / or caregivers were asked if they had noticed that their children and adolescents showed difficulty focusing, became easily bored, had excessive crying or irritability, worry, excessive sadness, regression to behaviors that had been outgrown or had discontinued activities they used to enjoy.

They were also asked if children and adolescents preferred going out or stay at home, if they had talked about not being able to go to school, if they watched the news together, and how they got information about the pandemic. For the latter questions, respondents were asked to provide a brief description of their feelings or experience. After the survey was completed, useful information was available through a web site created for this study in the following link: https:/ / linktr.ee/pediatriaypandemia.

Questionnaires were divided into 3 groups for analysis, based on the age group classification of the World Health Organization: preschoolers (3-5 years), school-aged children (6-11 years), and adolescents (12-15 years). The results were analyzed using the SPSS ${ }^{\circledR}$ statistical software, v.19.0 for Windows (SPSS Inc., Chicago, USA). Pearson's $\chi^{2}$ test and frequency tables were used, as applicable.

\section{Ethical aspects}

Participants signed an informed consent form for voluntary participation in this study (essential for inclusion). The study was carried out in accordance with the principles established in the Declaration of Helsinki (2013) and was approved by the Teaching and Research Committee of Hospital General de Agudos Dr. Juan A. Fernández.

\section{RESULTS}

A total of 873 questionnaires were sent and 1117 answers were collected. We believe that, by using a WhatsApp ${ }^{\circledR}$ link to disseminate the questionnaire and offering a site with useful information at the end, the survey may have experienced an exponential distribution. Out of 1117 questionnaires received, 37 were excluded because children did not correspond to the age range of the target population or because they lived outside the CABA. A total of 1080 questionnaires were included for result analysis. The characteristics of the sample are presented in Table 1.

In $93 \%$ of cases, questionnaires were completed by the father or mother. Of them, $46 \%$ had completed primary education; $14 \%$, secondary education; $11 \%$ tertiary education; and $7 \%$, university education.

Across all age ranges, most children were able to talk about how they felt about not being able to go to school. Among children aged 3-5 years, $76 \%$ talked about it, whereas in the 6-11 and 12-15-year-old groups, 94\% and 92\% did so, respectively. When respondents were asked to briefly describe what their children and adolescents said, across all age groups, $83 \%$ of them agreed that they missed being in contact with their peers; $68 \%$, that they felt anxious; and $72 \%$, that they were tired.

Approximately $60 \%$ of parents and/or caregivers of children younger than 11 years referred that they perceived that children became easily bored, like half of adolescents. In addition, parents and / or caregivers noticed changes in moods and behaviors. Among younger children, 
an increase in crying spells (52\%) and regression to behaviors that had been outgrown $(29 \%)$ was observed. Children aged 6-11 years showed difficulty maintaining focus levels $(43 \%)$ and those in the 12-15-year-old group discontinued activities they used to enjoy and showed sadness and / or worry (30\%) (Table 2).

In relation to allowed recreational outings, younger children referred that they wanted to do them $(81.5 \%)$, as well as $54 \%$ of children and adolescents aged 6-11 years; however, 6 out of 10 adolescents chose to stay at home.

In relation to how children got informed about the pandemic, it was observed that most preschoolers did not watch the news $(68 \%)$

In spite of this, almost all children received information, both about the current situation and the measures necessary to prevent virus dissemination from their parents, caregivers, and teachers. In the case of school-aged children, $48 \%$ of parents and/or caregivers decided not to expose children to the news and adapted the information that they considered their children needed to know, based on their age. Lastly, $66 \%$ of adolescents watched the news, shared the information with their close contacts, discussed it, and shared their opinions. They were also aware of the situation via the Internet and social media.

\section{DISCUSSION}

Throughout history, quarantine periods have been established in response to epidemics and disasters. Different investigations have demonstrated that a lockdown is a psychologically stressful situation. ${ }^{8,9}$ In relation to children, the suspension of classes and the interruptions in their daily routine may have a negative impact on their physical and mental health. Parents may also convey their anxiety to their children and have inappropriate parental behaviors, which may contribute to the development of post-traumatic stress symptoms in children.

A study published in 2003 about the severe acute respiratory syndrome (SARS) outbreak in Canada registered a prevalence of post-traumatic stress symptoms after a brief lockdown. ${ }^{10}$ In

TABLE 1. Sample characteristics $(n=1080)$

\begin{tabular}{lccc}
\hline Characteristic & $\begin{array}{c}\text { Preschoolers } \\
\mathbf{n = 2 2 2}\end{array}$ & $\begin{array}{c}\text { School-aged children } \\
\mathbf{n = 6 3 5}\end{array}$ & $\begin{array}{c}\text { Adolescents } \\
\mathbf{n = 2 2 3}\end{array}$ \\
\hline Sex & & & \\
$\quad$ Female & $98(44 \%)$ & $342(54 \%)$ & $120(54 \%)$ \\
$\quad$ Male & $124(56 \%)$ & $293(46 \%)$ & $103(46 \%)$ \\
Age & Mode: 3 years & Mode: 7 years & Mode: 12 years \\
& $(3-5$ years $)$ & $(6-11$ years $)$ & $(12-15$ years $)$ \\
Does the child have any underlying disease? & & & $89 \%$ \\
$\quad$ No & $91 \%$ & $5 \%$ & $11 \%$ \\
$\quad$ Yes & $9 \%$ & $97 \%$ & $92 \%$ \\
Is the child receiving any chronic treatment? & & $3 \%$ & $8 \%$ \\
No & $90 \%$ & $10 \%$ & \\
Yes & & & \\
\hline
\end{tabular}

TABLE 2. Mood or behaviors during lockdown

\begin{tabular}{lccc}
\hline & Preschoolers $\%$ & School-aged children $\%$ & Adolescents $\%$ \\
\hline Trouble focusing & $26(\mathrm{n}=57)$ & $43(\mathrm{n}=274)$ & $36(\mathrm{n}=80)$ \\
Easily bored & $60(\mathrm{n}=134)$ & $64(\mathrm{n}=404)$ & $51(\mathrm{n}=113)$ \\
Excessive crying or irritability & $52(\mathrm{n}=116)$ & $35(\mathrm{n}=225)$ & $29(\mathrm{n}=65)$ \\
Excessive sadness or worry & $14(\mathrm{n}=30)$ & $17(\mathrm{n}=110)$ & $30(\mathrm{n}=66)$ \\
Regression to behaviors that had been outgrown & $29(\mathrm{n}=64)$ & $13(\mathrm{n}=82)$ & $9(\mathrm{n}=19)$ \\
Discontinuation of activities they used to enjoy & $14(\mathrm{n}=30)$ & $25(\mathrm{n}=158)$ & $48(\mathrm{n}=99)$ \\
You have not noticed any of the above & $20(\mathrm{n}=45)$ & $17(\mathrm{n}=110)$ & $22(\mathrm{n}=50)$ \\
\hline
\end{tabular}


addition, in 2014, it was observed that lockdown measures related to the Ebola outbreak in rural areas of Sierra Leone caused psychological stress in relation to cultural habits. ${ }^{11}$ Regarding the current COVID-19 pandemic, Qiu et al. described that lockdown measures established in China triggered a broad variety of psychological problems, including panic disorder, anxiety, and depression. ${ }^{12}$

As in the studies mentioned here, this study found evidence of changes in the mood and behaviors of children, which vary depending on the age group involved. Younger children show higher levels of irritability, regression to developmental milestones that had been outgrown, and expression of negative feelings, including sadness. As age increases, children worry not only about disease but the difficulty to, for example, focus on daily activities, such as school. Among adolescents, almost half of respondents found limitations to carry out the activities they used to enjoy. This means that, as what has been reported by the survey conducted by the United Nations International Children's Emergency Fund (UNICEF) about the impact of COVID-19 on mental health of adolescents and youth, half of them were less motivated to do activities they usually enjoyed. ${ }^{13}$ Boredom and reluctance among youth were also referred in different studies conducted in our country. ${ }^{14,15}$ It is worth noting that a large percentage of children and adolescents across the 3 age groups were able to talk about their feelings in relation to missing in-person classes, or at least that is what their parents perceived. As with the survey conducted by the Sociedad Argentina de Pediatría about the perceptions and feelings of Argentine children during the lockdown, ${ }^{16}$ children referred missing contact with their peers. Negative feelings, such as sadness, boredom, anxiety, and worry, prevailed over positive ones.

Lastly, it is very important to know how children receive information about the pandemic and how they process it based on their age. A large percentage of surveyed parents screened the information or selected the content they wanted to share with their children, especially younger ones. However, adolescents showed interest in keeping up with the information.

Pandemics and the subsequent disease containment efforts may create conditions that families and children may find traumatic. Since pandemics are unique, they require specific response strategies to warrant the behavioral health needs of children and their families. Plans to face a pandemic should approach such needs and disease containment efforts. Such plans should have a holistic perspective that encompasses the concept of health in its broad biopsychosocial sphere. It is necessary to consider the evidence about how the child and adolescent population is affected by the COVID-19 pandemic to design action plans that minimize the impact. ${ }^{17,18}$

In relation to the methodological design of this study, as mentioned above, the questionnaire was self-administered and using a rapid information registration form, taking into account the limitations of such data collection tools. The most notable limitations of conducting online questionnaires include a gap between the general population and that with the possibility of accessing such questionnaires; problems in representativity, broadened by the absence of sample randomization criteria; lack of or problems to resolve geographical coverage; and the differences between completing a self-administered survey and that guided by an interviewer, among others.

\section{CONCLUSIONS}

The COVID-19 pandemic and the mandatory social isolation policy impacted on the mood, behaviors, and emotions of children and adolescents. Negative feelings prevailed, such as boredom, sadness, anxiety, and worry.

Children and adolescents received information about the COVID-19 pandemic; in the case of younger children, information was adapted by their parents, caregivers, and teachers. Adolescents received information through traditional media and social networks instead.

\section{REFERENCES}

1. Argentina. Ministerio de Salud. Nuevo coronavirus Covid 19. ¿Qué medidas está tomando el gobierno? [Accessed on: September $\left.20^{\text {th }}, 2021\right]$. Available at: https://www. argentina.gob.ar/coronavirus / medidas-gobierno

2. Resolución 108/2020. Ministerio de Educación. Boletín oficial de la República Argentina. Buenos Aires, 15 de marzo de 2020. [Accessed on: September 20 ${ }^{\text {th }}, 2021$ ]. Available at: https:/ / www.boletinoficial.gob.ar/detalleAviso/ primera / 226752/20200316

3. Cluver L, Lachman JM, Sherr L, Wessels I, et al. Parenting in a time of COVID-19. Lancet. 2020; 395(10231):e64.

4. Unicef Argentina. ¿Cómo afecta el aislamiento social, preventivo y obligatorio a los hogares con discapacidad? Encuesta COVID-19. Informe de resultados. [Accessed on: September $\left.20^{\text {th }}, 2021\right]$. Available at: https: / / www.unicef. org/argentina/media/8871/ file

5. Dalton L, Rapa E, Stein A. Protecting the psychological health of children through effective communication about 
COVID-19. Lancet Child Adolesc Health. 2020; 4(5):346-7.

6. Instituto Nacional de Estadísticas y Censos. Cuadros estadísticos. Estimaciones y proyecciones de población. Total, del país. 2010-2040. [Accessed on: September $20^{\text {th }}$, 2021]. Available at: https://www.indec.gob.ar/indec/ web / Nivel4-Tema-2-24-84

7. Dirección General de Estadística y Censos. Gobierno de la Ciudad de Buenos Aires. Proyecciones de población por grupo de edad y comuna según sexo. Ciudad de Buenos Aires. Años 2010/2025. [Accessed on: September 20 ${ }^{\text {th }}$, 2021]. Available at: https:/ / www.estadisticaciudad.gob. ar / eyc / ? $=79970$

8. Sprang G, Silman M. Posttraumatic stress disorder in parents and youth after health-related disasters. Disaster Med Public Health Prep. 2013; 7(1):105-10.

9. Demaria F, Vicari S. COVID-19 quarantine: Psychological impact and support for children and parents. Ital J Pediatr. 2021; 47(1):58.

10. DiGiovanni C, Conley J, Chiu D, Zaborski J. Factors influencing compliance with quarantine in Toronto during the 2003 SARS outbreak. Biosecur Bioterror. 2004; 2(4):26572 .

11. Caleo G, Duncombe J, Jephcott F, Lokuge K, et al. The factors affecting household transmission dynamics and community compliance with Ebola control measures: a mixed-methods study in a rural village in Sierra Leone. BMC Public Health. 2018; 18(1):248.

12. Qiu J, Shen B, Zhao M, Wang Z, et al. A nationwide survey of psychological distress among Chinese people in the COVID-19 epidemic: implications and policy recommendations [published correction appears in Gen
Psychiatr. 2020 Apr 27;33(2):e100213corr1]. Gen Psychiatr. 2020; 33(2):e100213.

13. Unicef. El impacto del COVID-19 en la salud mental de adolescentes y jóvenes. 2020. [Accessed on: September $\left.20^{\text {th }}, 2021\right]$. Available at: https: / / www.unicef.org/lac/elimpacto-del-covid-19-en-la-salud-mental-de-adolescentesy-jóvenes

14. Schnaiderman D, Bailac M, Borak L, Comar H, et al. Impacto psicológico del aislamiento por COVID-19 en jóvenes de San Carlos de Bariloche, Argentina: la mirada de los padres. Arch Argent Pediatr. 2021; 119(3):170-6.

15. Cabana JL, Pedra CR, Ciruzzi MS, Garategaray MG, et al. Percepciones y sentimientos de niños argentinos frente a la cuarentena COVID-19. Arch Argent Pediatr. 2021;119(4):S10722.

16. Subcomisión de Derechos del Niño, Comité de Pediatría Social. Percepciones y Sentimientos de Niños Argentinos frente a la Cuarentena COVID-19. Resultados Preliminares. Sociedad Argentina de Pediatría. 2020. [Accessed on: September $\left.20^{\text {th }}, 2021\right]$. Available at: https: / / www.sap.org. ar/uploads/archivos/general / files_doc-percepciones-ysentimientos-de-ninos-argentinos-frente-a-la-cuarentenacovid-19_1606056649.pdf

17. Paricio del Castillo R, Pando Velasco MF. Salud mental infanto-juvenil y pandemia de Covid-19 en España: cuestiones y retos. Rev Psiquiatr Infant Juv. 2020; 37(2):30-44.

18. Brooks SK, Webster RK, Smith LE, Woodland L, et al. The psychological impact of quarantine and how to reduce it: rapid review of the evidence. Lancet. 2020; 395(10227):91220. 
ANNEX

Questionnaire

CHILDHOOD AND THE PANDEMIC

Due to the COVID-19 pandemic, children have experienced several changes in their daily routine; for this reason, we are studying the impact of this situation on children and invite you to complete this brief survey. Thank you.

Consent: I am of legal age and wish to participate voluntarily.*

* The study was approved by the Ethics Committee of Hospital General de Agudos Dr. Juan A. Fernández.

If you have any question about your rights as a research subject, please write to: fernandez_cei@buenosaires.gob.ar

Yes

No

\section{GENERAL INFORMATION}

Child's age*

Child's sex*

Male

Female

Relationship of the person completing the survey with the child*

Father / mother

Grandfather/grandmother

Uncle/aunt

Brother/sister

Other:

Level of education of the child*

Preschool education

Primary education

Secondary education

Other:

Level of education of the person completing the survey*

Incomplete primary education

Complete primary education

Incomplete secondary education

Complete secondary education

Incomplete tertiary education

Complete tertiary education

Incomplete university education

Complete university education

Does the child have any underlying/previous/known disease? *

Yes

No

If Yes, what disease(s)? Please, specify:

Does the child receive any medication? *

Yes

No

If Yes, what medication(s)? Please, specify: 


\section{MENTAL HEALTH}

Have you noticed any of the following in your child? (You may select more than one)*

Trouble focusing

Easily bored

Excessive crying or irritability

Excessive sadness or worry

Regression to behaviors that had been outgrown

Discontinuation of activities they used to enjoy

When it's time to leave the house, does your child prefer to stay at home?*

Yes

No

Has your child described how they feel about not being able to go to school? Please, describe briefly:*

Do you watch the news together? Is the child informed about the pandemic? Please, describe briefly:* 